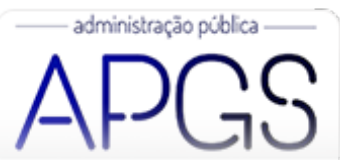

Administração Pública e Gestão Social ISSN: 2175-5787

apgs@ufv.br

Universidade Federal de Viçosa

Brasil

\title{
Gestão Pública no Brasil, Conquistas Recentes e Dilemas Presentes
}

\author{
Levy, Evelyn \\ Gestão Pública no Brasil, Conquistas Recentes e Dilemas Presentes \\ Administração Pública e Gestão Social, vol. 11, núm. 4, 2019 \\ Universidade Federal de Viçosa, Brasil \\ Disponível em: http://www.redalyc.org/articulo.oa?id=351560525013
}

Esta obra está bajo una Licencia Creative Commons Atribución-NoComercial-SinDerivar 3.0 Internacional. 


\section{Gestão Pública no Brasil, Conquistas Recentes e Dilemas Presentes}

\author{
Evelyn Levy \\ Comitê Cientifico do Congresso do Conselho Nacional de \\ Secretários de Estado da Administração, Brasil \\ evelyn.levy@uol.com.br
}

Redalyc: http://www.redalyc.org/articulo.oa? $\mathrm{id}=351560525013$

Ao que tudo indica, encontramo-nos mais uma vez em um momento de inflexão histórica. O paradigma, vigente de modo mais ou menos abrangente desde o final da Segunda Guerra, parece ter se progressivamente diluído nos países ocidentais. O impacto das novas tecnologias e importantes mudanças geopolíticas trouxeram consequências imprevistas nos plano social, cultural e econômico. Essa porção do globo vive hoje uma fase de baixo crescimento econômico, desigualdade crescente, mercados de trabalho em profunda transformação, grande insatisfação dos seus cidadãos com os serviços públicos e forte desconfiança com respeito à democracia.

Ainda que com características que lhe são específicas, o Brasil não escapa desse processo mais amplo: tem que se confrontar com os desafios em que a competição internacional se tornou mais acirrada, assentada em novíssimas bases, tendo porém um "passivo" não resolvido, que se traduz nas históricas e profundas desigualdades sociais. Tem pois de operar em meio a um ambiente econômico recessivo que acentua sua crise fiscal e fazer frente aos conflitos sociais que se aprofundam. Todas essas "falhas de governança coletiva" impõem severos desafios à Gestão Pública.

Após o período daspiano, em que se fundaram as bases de uma administração pública profissional de concretização restrita - e o período militar, que gestou o decreto-lei 200 e o complexo de empresas estatais, que objetivaram modernizar a infraestrutura do país, a Gestão Pública tomou novos contornos com a Constituição de 1988. Refletindo os movimentos em favor da democracia e da justiça social, a Carta Magna procurou fortalecer a Gestão Pública ao: promover a participação e a descentralização de responsabilidades aos estados e municípios, colocando-as mais próximas aos cidadãos. Ao mesmo tempo, impôs a realização de concursos públicos - em combate ao clientelismo ainda muito disseminado- e o planejamento governamental, através da adoção do Plano Plurianual/PPA, atrelado ao orçamento. A criação e proteção de uma burocracia profissional para todas as atividades estatais também se fizeram presentes nas regras da estabilidade e da ampla previdência .

Os anos 90 iniciaram em meio a uma profunda crise fiscal, que se revelava através de elevadíssimos índices de inflação. As respostas advindas por parte do primeiro governo eleito após o período militar - Collor - foram de denegrir o funcionalismo público e responsabiliza-lo pelos constrangimentos fiscais. Com a renúncia do presidente, arrefecem os movimentos contrários à administração pública.

O governo FHC, iniciado em 1995, procurou dar uma resposta ampla e efetiva para os grandes desafios da administração pública brasileira: torna-la despolitizada e profissional, torna-la eficiente, eficaz e menos dispendiosa, democrática e transparente. A "administração gerencial", proposta pelo Ministério da Administração e Reforma do Estado/MARE, sob a tutela do Ministro Luiz Carlos Bresser Pereira, propunha uma nova estrutura para o Estado Brasileiro:

- um núcleo estratégico, responsável pela elaboração, monitoramento e avaliação das políticas públicas

- agências executivas, organizações estatais responsáveis por serviços exclusivos de Estado 
- organizações sociais/OSs, ou seja, organizações do terceiro setor, responsáveis pela oferta de serviços não exclusivos, mas determinantes para o desenvolvimento da nação, tais como Educação, Saúde, Cultura, Meio Ambiente e outros.

Agências e OSs teriam maior autonomia administrativa e recursos transferidos em troca do alcance de resultados previamente acordados com o núcleo estratégico. No que diz respeito aos regimes de trabalho, as OSs implicavam em contratos CLT, enquanto no núcleo estratégico e nas agências prevaleceriam os funcionários estatutários, organizados nas carreiras de Estado. A maior parte das mudanças propostas no "Plano Diretor da Reforma do Estado" foram incluídas na EC 19/98, embora alguns de seus artigos não tenham jamais sido regulamentados; tal é o caso da demissão por insuficiência de desempenho e do emprego público.

A "reforma gerencial" constituía portanto uma resposta aos reclamos da baixa resolutividade da administração pública, procurando ao mesmo tempo contornar os elevados custos que representavam as regras abrangentes de contratação e aposentadoria do funcionalismo. Os governos FHC acabaram por avançar pouco na implementação dessas ideias, que representavam uma mudança bastante profunda frente à tradição daspiana ainda prevalecente.

A persistente crise fiscal, a despeito da conquista da estabilidade monetária, induziu principalmente os estados a adotarem uma grande parte dos postulados da "reforma gerencial", a partir de 2003. A adoção dos novos modelos organizacionais, não- estatais, se espraiou pela maior parte dos estados e muitos municípios, em setores tais como a Saúde principalmente, mas também Cultura, Assistência Social e Meio Ambiente. Um grande número de estados, e também municípios, criou carreiras horizontais de "gestores".

Com a melhoria das finanças públicas foi possível promover muitos concursos públicos. Entre 1995 e 2016 o número de civis e militares no nível federal aumentou 25\%, totalizando 1,2 milhão; no nível estadual o crescimento foi de $28 \%$, passando para 3,7 milhões e no nível municipal o crescimento foi de $175 \%$, chegando a 6,5 milhões (IPEA, 2018). O crescimento exponencial nos municípios representou, em larga medida, a pretendida descentralização e ampliação dos serviços educacionais (como a pré-escola) e de saúde ( como os equipamentos de atenção básica). Não por acaso, o maior número de servidores concursados, no período, foi de professores.

Uma das marcas do período foi a ampliação do número de "escolas de governo", para a educação continuada dos servidores, em paralelo ao aumento muito significativo do número de cursos de graduação e pós-graduação em Administração Pública. Pode-se observar um nítido avanço na qualificação dos servidores, especialmente nos níveis federal e estadual. Ao mesmo tempo, a produção de conhecimento nesse campo do qual essa revista é uma evidência - ganhou uma escala nunca vista. Muitos desses entes também induziram a maior participação dos servidores na melhoria dos serviços, por meio de prêmios de inovação.

A adoção das novas tecnologias de informação e comunicação foi importante, embora inicialmente mais intensa do que no período subsequente. "Lojas do cidadão", concentrando a oferta de serviços burocráticos em mesmos espaços físicos, se disseminaram em vários estados. Houve avanços no campo das compras governamentais, ensejando economias consideráveis pela adoção, por exemplo, do modelo "pregão". Menos relevantes foram os avanços no âmbito do planejamento e na área orçamentária, especialmente na esfera federal.

O período que se seguiu à formulação e à implantação, ainda que parcial, da "reforma gerencial", deixou um legado importante, mas ambivalente: de modo muito mais amplo, uma burocracia selecionada por concursos públicos e incomparavelmente mais qualificada. Uma visão um pouco menos burocrática da gestão de pessoas. Melhoria nos processos de trabalho, especialmente pela utilização das TICs; uma internalização do conceito de "resultados"; avanços na transparência das informações governamentais.

Entretanto, por variados motivos, a oferta de serviços públicos passou a ser bastante criticada, dando origem a vigorosas manifestações sociais, a partir de 2013. Investigações policiais, facilitadas pelas novas legislações e instrumentos disponibilizados, expuseram um amplo processo de corrupção, aprofundando 
o descontentamento da população com a administração pública. O declínio das receitas governamentais, em virtude da queda de demanda por commodities, tornou gravíssimo o déficit fiscal, especialmente impulsionado pela previdência inclusive pública. O padrão de "presidencialismo de coalizão", assentado na entrega de cargos comissionados para partidos da base, facilitou a ocupação de cargos gerenciais por quadros nem sempre capacitados para tal fim. Raras foram as políticas públicas que estabeleceram resultados a serem alcançados, como a Educação Fundamental, através do IDEB. Em razão da desconfiança da sociedade com a lisura das atividades governamentais, os controles exacerbaram sua ação, a ponto de inibir a gestão, levandoa com frequência à parilisia.

Às vésperas das eleições majoritárias de 2018, um grupo de especialistas em Gestão Pública, com experiência em diversos de seus aspectos e operando em diferentes locais do território nacional, ofereceu à sociedade e aos candidatos um rol de sugestões para a melhoria da administração pública ${ }^{[1]}$. Entre suas recomendações, podemos destacar:

- o amplo uso da gestão por resultados, com a avaliação contínua das políticas, programas e serviços produzidos

- a reestruturação do planejamento governamental

- o aperfeiçoamento dos processos de coordenação governamental

- a qualificação da elaboração e gestão de projetos

- a promoção da inovação

- a seleção de dirigentes públicos

- a flexibilização de regras na área de RH, inclusive a criação do emprego público

- o fomento de parcerias

- o aprofundamento do governo digital

- o uso estratégico das compras governamentais

- o avanço da digitalização do serviços e processos

- o aumento da transparência, da participação e do controle social.

Dentre os itens acima elencados, vale notar que a seleção de dirigentes públicos mereceu especial atenção por parte da sociedade civil, que passou a apoiar governos - especialmente estaduais - para identificar quadros competentes, dentro e fora da administração pública, para ocupar postos gerenciais estratégicos para o andamento das principais políticas públicas.

Tanto o Congresso, quanto o Executivo Federal elaboram, nesse momento, propostas de requalificação da administração pública. Assim, o Senado elaborou o novo marco das agências reguladoras, colocando obstáculos às indicações políticas. A Câmara dos Deputados discute a nova lei de licitações, na qual se insere uma nova modalidade para aquisições de TI: o diálogo competitivo. A Câmara também discute os "supersalários”, salários acima do teto.

De acordo com "Congresso em Foco"(16/8/2018), o Governo Bolsonaro prepara uma reforma administrativa, a ser submetida após a aprovação das reformas da previdência e tributária. Essa reforma, supostamente, deverá enfrentar a rigidez das regras da gestão de pessoas:

- diminuindo os concursos públicos para ocupação de cargos efetivos

- apoiando as contratações temporárias

- tornando as carreiras horizontais e facilitando a mobilidad

- diminuindo o número de carreiras, estruturas e órgãos

- apoiando a criação de fundações privadas, as OSs, os Serviços Sociais Autônomos, vinculados através de contratos de gestão.

Em conclusão, é possível afirmar que, embora a atual conjuntura apresente grandes desafios à administração pública, as décadas passadas criaram uma base de pessoas, processos e conhecimentos que permitiriam à 
Evelyn Levy. Gestão Pública no Brasil, Conquistas Recentes e Dilemas Presentes

Gestão Pública se tornar uma força motriz para o desenvolvimento nacional. Serão necessários forte liderança e alinhamento entre atores políticos e sociedade para estabelecer rumos e assim demandar o desempenho da máquina pública.

\section{Notas}

1 O documento "Um Novo Patamar para a Gestão Pública Brasileira” foi apresentado em um Seminário no Instituto de Estudos Avançados (IEA) da USP, no dia 20 de setembro de 2018. Elaborado por 17 especialistas, o texto está em diversas páginas e links da internet, como este do IEA: http://www.iea.usp.br/eventos/documentos/um-novo-patamarpara-a-gestao-publica-brasileira/view .

\section{BY-NC-ND}

